\title{
On the Social Nature of Objectivity: Helen Longino and Justin Biddle*
}

\author{
Jaana EIGI
}

Received: 23/11/2014

Final Version: 19/02/2015

BIBLID 0495-4548(2015)30:3p.449-463

DOI: $10.1387 /$ theoria. 13208

ABSTRACT: According to Helen Longino, objectivity is necessarily social as it depends on critical interactions in community. Justin Biddle argues that Longino's account presupposes individuals that are completely open to any criticism; as such individuals are in principle able to criticise their beliefs on their own, Longino's account is not really social. In the first part of my paper I argue that even for completely open individuals, criticism for maintaining objectivity is only possible in community. In the second part I question Biddle's interpretation of Longino's conception of the individual. I conclude that objectivity as Longino describes it is necessarily social.

Keywords: Biddle, Collins, criticism, epistemic subject, Kusch, Longino, objectivity, rule-following, social epistemology, tacit knowledge.

RESUMEN: Según Helen Longino, la objetividad es necesariamente social puesto que depende de interacciones críticas en una comunidad. Justin Biddle defiende que la explicación de Longino presupone individuos que están enteramente abiertos a cualquier crítica; y, puesto que estos individuos son en principio capaces de someter a crítica sus creencias por sí mismos, la explicación de Longino no es realmente social. En la primera parte de mi artículo defiendo que incluso para individuos enteramente abiertos, la crítica para el mantenimiento de la objetividad solo es posible en una comunidad. En la segunda parte pongo en cuestión la interpretación de Biddle sobre la concepción del individuo de Longino. Concluyo que la objetividad, tal y como la describe Longino, es necesariamente social.

Palabras clave: Biddle, Collins, crítica, sujeto epistémico, Kush, Longino, objetividad, epistemología social, seguir-una-regla, conocimiento tácito.

\section{Introduction}

The interest of contemporary philosophy of science towards social aspects of science is indisputable; however, the way to specify these social aspects and to understand the claim that science is social is very much a matter of dispute. The aim of my paper is to contribute to this discussion by addressing the argument Justin Biddle (2009) has recently suggested concerning Helen Longino's (1990; 2002) account of objectivity. While responding to Biddle's argument is the primary aim of the paper, doing so I make a more general sugges-

* This research was supported by European Social Fund's Doctoral Studies and Internationalisation Programme DoRa, which is carried out by Foundation Archimedes. I would like to thank Endla Lõhkivi, Martin Kusch, the audience at the EPSA13 conference in Helsinki, participants of the doctoral seminar in philosophy at the University of Tartu and the anonymous reviewers for helpful comments. 
tion that assessing one's and others' claims in light of intersubjective norms and alternative perspectives as a part of being objective is impossible without community and in this sense it is essentially social.

In his paper, Biddle presents a powerful argument against the characterisation of Longino's account as social. He argues that implicit in Longino's account is a particular conception of the individual. According to this conception, the individual has capabilities that make social interactions unnecessary for maintaining objectivity-such individuals can in principle do it on their own. Thus, Longino's claim about the fundamentally social nature of her account is refuted; social interactions may be useful in practice but are not strictly necessary in principle. Biddle suggests that social epistemology should employ a different conception of the individual that is compatible with a fully social account of science, and describes briefly how such an account could look like.

In my paper, I argue for the fundamentally social nature of Longino's approach to objectivity. In the first part of my argument, I discuss whether the individuals that according to Biddle are presupposed by Longino's account would be able to achieve objectivity in isolation. I argue that they would not: community would be required for objectivity even in case of such individuals. In the second part, I engage with Biddle's interpretation of Longino's conception of the individual directly and argue that the textual and contextual support for it is not unambiguous. Instead, there is evidence for a different conception and this alternative conception supports the characterisation of Longino's account as social. I conclude that both arguments support the claim that sociality is necessary for objectivity in Longino's approach; objectivity in the sense that Longino discusses cannot be asocial.

In the following part of the paper, I describe Longino's account of objectivity and summarise Biddle's argument against her claim that objectivity, so understood, is social and can only be fully realised in community. In the third part, I argue that two crucial aspects of objectivity, as Longino and Biddle discuss it, require socialisation and belonging to community even if the individual is understood in the way that Biddle ascribes to Longino. Developing this argument I draw on Harry Collins's (2010) account of strong collective tacit knowledge and Martin Kusch's (2002) account of rule-following. In the concluding part of the paper I discuss the evidence for an alternative conception of the individual in Longino's account, suggesting that some aspects of Longino's conception that Biddle overlooks share important similarities with the conception Biddle himself defends as appropriate for social epistemology.

\section{Longino's account of objectivity and Biddle's criticism}

Before discussing Longino's account of objectivity and Biddle's criticism it is helpful to clarify how objectivity is understood in Longino's account (Biddle does not discuss the meaning of objectivity as a separate issue and his usage follows Longino's). In her discussion of objectivity, Longino (1990, 62-66) distinguishes between its two senses. In one sense, objectivity is connected with the notion of truth: to be objective (for a hypothesis) is to represent the facts of the world truthfully. In another sense, objectivity is understood as the opposite of subjectivity: to be objective (for a method or for a hypothesis achieved as the result of its application) is to rely on non-subjective or non-arbitrary criteria. Elsewhere, Longino defines the latter sense of objectivity as "independence from subjective 
bias" (Longino 1990,75) and freedom from "intrusion of individual subjective preference" (Longino 1990, 76). It is this sense of objectivity that Longino is concerned with.

The problem of objectivity is salient for Longino due to her account of evidential reasoning (Longino 1990, 38-48 and 2002, 124-28). As Longino argues, a state of affairs does not determine a unique hypothesis that would explain it: alternative hypotheses are possible on the basis of the same evidence. In order to fill in this logical gap, evidential reasoning must inevitably rely on some background assumptions in light of which a certain state of affairs can be seen as evidence for a particular hypothesis. However, if evidential reasoning always involves background assumptions, subjective biases can influence acceptance of hypotheses via those assumptions.

Longino argues that this danger can be avoided, and objectivity maintained, thanks to the social nature of knowledge production (Longino 1990, 66-76). Before being recognised as a part of public knowledge, individuals' claims are subject to scrutiny by other members of knowledge-producing community. Claims are criticised, modified, cited in agreement or disagreement, extended and tested in new situations. In this process, initial claims are modified towards greater intersubjective acceptability-problematic idiosyncratic assumptions behind them are exposed and must then be defended, modified or abandoned. Collective criticism thus allows for explication and subsequent modification of assumptions that might otherwise remain hidden for their bearer.

Longino thus argues that in order for objectivity to be possible, critical dialogue in community is necessary. However, different communities may be better or worse at supporting collective criticism that sustains objectivity. For example, exposing problematic assumptions may be relatively ineffective if community does not encourage free critical interactions. Moreover, while critical dialogue may be generally effective for blocking individual biases, biases shared by entire community may remain hidden. To address the first problem, Longino suggests four criteria that allow judging conditions for criticism in a community: availability of venues for presenting criticism, community's responsiveness to criticism (uptake), existence of shared norms that allow assessing the relevance of criticisms and adequacy of responses, and (tempered) equality of intellectual authority between participants (Longino 1990, 76-81 and 2002, 129-35). To address the second problem, Longino discusses availability of different perspectives as another important condition for objectivity. As Longino stresses, underrepresentation of certain social groups in scientific community, like women and members of minority groups in Western countries, and underappreciation of non-Western science in the West constitute a problem for objectivity because they limit the number of perspectives recognised in scientific community (Longino 1990, 78-79 and 2002, 132). Openness of community to potentially relevant perspectives plays a crucial role for preventing collective blind spots with respect to shared assumptions.

To sum up, objectivity is seen in Longino's account as emerging on the basis of socialinteractive-practices in community that is to follow certain social norms; these social interactions make it possible to block influence of subjective biases in a way that is unachievable for an individual. Objectivity is thus seen as a property of communities rather than of individuals. This is the sense in which Longino's account of objectivity is social.

In his paper, Biddle (2009) challenges this view and argues that the conception of the individual that Longino's account presupposes conflicts with Longino's characterisation of objectivity as necessarily social. Biddle suggests that Longino's criteria depict objective com- 
munity as realising John Stuart Mill's ideal of the "free marketplace of ideas" (Biddle 2009, 613 and 614-15) and that Longino's account is deeply embedded in Mill's political liberalism (Biddle 2009, 615-16). In turn, this connection is crucial for Biddle's interpretation of Longino's criterion of uptake (responsiveness to criticism). Biddle $(2009,616)$ suggests that this criterion could be interpreted in two different ways. In what he calls the individualistic interpretation, it is applied on the level of individuals - for community to satisfy the requirement of uptake, most of its members must satisfy it. In the social interpretation of uptake, it operates on the level of community-for community to satisfy this requirement, community as a whole must be responsive to criticism, without each individual member necessarily being so responsive.

Biddle argues that while Longino does not specify how uptake should be interpreted, there are strong reasons to think that her account requires the individualistic interpretation. First, Biddle reads Longino's account as stressing the importance of individuals' actions, which supports the interpretation of uptake as demanding responsiveness on the individual level. As an example, he quotes Longino's statement that "[w] hat is required is that community members pay attention to the critical discussion taking place and that the assumptions that govern their group activities remain logically sensitive to it" (Longino 1990, 78 quoted in Biddle 2009, 617). Second, Biddle argues that Longino's account shares the conception of the individual with Mill's. In turn, he reads Mill's argument for free speech as describing as the ideal the individual that is very responsive to criticism-the individual that "listen[s] to all that could be said against him" and for each of his opinions studies "all modes in which it can be looked at by every character of mind" (Mill 1859/1978, 19, quoted with emphasis in Biddle 2009, 617). Biddle concludes that Mill's ideal presupposes individuals that are open to any criticism from any source and are able to question any of their beliefs, and this is also what Longino's criterion of uptake requires-a community that satisfies the criterion of uptake must mostly consist of individuals that are open to everything (Biddle 2009, 617-18).

In the decisive step of his argument, Biddle points out that such radically open individuals are in principle able to criticise their beliefs exhaustively and impartially on their own. Social interactions may facilitate this process but are not fundamentally necessary. There is nothing in such individuals (whom Biddle likens to "unencumbered selves" (Biddle 2009, 618) discussed in moral and political philosophy) that could prevent the same effective criticism from being fully realised by the isolated individual. As Biddle writes $(2009,619)$,

But if individuals, in the ideal, are completely open-minded-if they are capable of questioning all their beliefs, of examining evenhandedly all potential weaknesses in their views, and of adjudicating between opposing beliefs, methodologies, evaluative criteria, and so on, in a fair and evenhanded manner-then it is false that a community is necessary for the justification of beliefs. For such individuals are perfectly capable, at least in principle, of evaluating lines of argument in an objective fashion-and of doing so on their own, qua individuals.

Accordingly, Biddle concludes that Longino's claim about objectivity being necessarily social is proven wrong, as the individual her account presupposes can fully achieve objectivity independently from community. He suggests that developing a truly social account of knowledge would require abandoning the conception of the "unencumbered self" and the free marketplace of ideas as the ideal for scientific community (Biddle 2009, 620). 
I challenge Biddle's conclusion by presenting two separate arguments. Developing the first of them, I acknowledge that it is possible to interpret Longino's account so that the satisfaction of the criterion of uptake would ideally require each individual respond to criticism with the complete openness of the "unencumbered self". This possibility is prima facie plausible even without assuming that Longino's conception of the individual is the same as Mill's (and that Biddle interprets the latter correctly). On both interpretations of the criterion of uptake, for a community to be responsive to criticism at least some of its members must be responsive to it. Presumably, the more there are such individuals and the more each of them is open to criticism, the greater community's responsiveness is. One can thus reach the conclusion that the ideal community will entirely consist of individuals that are completely open to any criticism. Nevertheless, I intend to argue that even for such "unencumbered selves" that can impartially evaluate all of their beliefs, the kind of criticism Longino describes is only possible to the full extent in community. Doing so, I go beyond Longino's text and the authors she draws upon and turn to works on tacit knowledge and rule-following. Accordingly, the next section is best seen as a discussion of the general question whether the "unencumbered self" on its own is capable of objectivity as Longino describes it. Biddle's argument presupposes the response in the affirmative; I argue against this possibility and through that against Biddle's conclusion. I postpone questioning Biddle's interpretation of Longino's conception of the individual until the final part of my paper where I develop the second line of argumentation.

\section{Criticism for maintaining objectivity, collective tacit knowledge and rule-following}

The argument I propose in this part of the paper focuses on two aspects of criticism for maintaining objectivity that Longino and Biddle discuss. This criticism, as Longino describes it, involves, first, evaluation of beliefs in light of some norms, so that one is accountable to something beyond one's subjective preferences. This is the issue that Longino's criterion of availability of shared norms addresses. ${ }^{1}$ Second, it involves evaluation of beliefs and points of view in light of alternative beliefs and perspectives, so that one's problematic assumptions may become visible. This is the issue that Longino's requirement of diversity of perspectives in community addresses. Discussing the kind of criticism the "unencumbered self" supposedly can develop in isolation, Biddle describes similarly that such criticism would involve evaluating one's beliefs by taking into account both alternative criteria and alternative beliefs (Biddle 2009, 619). The aim of this part is to argue that both varieties of criticism require socialisation in community and further participation in community's life in order to acquire relevant knowledge and to continue to use it correctly. Develop-

${ }^{1}$ Longino's idea of norms is wide-she describes them as "encompass[ing] everything discussed as methodology by philosophers of science and more" (Longino 2002, 145). Following this wide usage, the notion of norms that I use in the paper includes, along with general norms of reasoning, more local norms, standards of evidence, argumentation and analysis, use of particular methods and rules of good practice that characterise a particular area of inquiry at a particular time. While the general norms are unlikely to change in the individual's lifetime, more local standards evolve faster-for example, individuals who entered biomedical community before and after randomised trials became the standard would acquire different norms. 
ing this argument, I draw on accounts of tacit knowledge (when discussing learning of rules and perspectives) and rule-following (when discussing their application). I conclude that the kind of criticism possible in community is not possible for an isolated individual.

There is a long tradition of discussing knowledge of rules as necessarily involving tacit knowledge. On the more abstract level there is the idea that "rules of action do not contain the rules for their application", as Collins $(2010,2)$ characterises the approach to tacit knowledge he connects with Ludwig Wittgenstein's ideas. Even after the rule has been stated in an explicit form, one has to know how to apply it, how to adapt its use to a particular context, how to judge the application of the rule as acceptable or unacceptable, both in known and novel situations, in short, what the rule means in each particular case. ${ }^{2}$ As an attempt to further explicate the rule would raise the same problems on the next level and lead to an endless regress, one has to admit that knowing and applying rules successfully involves knowledge that goes beyond their verbal formulation. On a less abstract level, the classical discussion of tacit knowledge by Michael Polanyi stresses how learning the language of a particular discipline (including, I suggest, its norms and standards of performance), is impossible without learning "what is meant" by it, without acquiring relevant tacit knowledge. ${ }^{3}$

Knowledge of shared norms that forms an important part of Longino's account of objectivity can thus be seen-like a case of knowing rules in general - as involving some tacit knowledge. In order to make clearer what type of tacit knowledge is involved in learning rules and norms, I propose using Collins's (2010) account. With the help of this account it is possible to demonstrate that community is necessary for learning rules without which criticism for sustaining objectivity is impossible. It is important to stress that I do not assume full compatibility between Longino's and Collins's accounts (particularly their conceptions of the individual as an epistemic subject). Instead, the point I want to make is that, insofar as the knowledge of shared norms plays a role in Longino's approach to objectivity, discussion of tacit knowledge is relevant and Collins's account provides some helpful distinctions.

According to Collins, several kinds of tacit knowledge can be distinguished depending on different senses of explication and on different kinds of obstacles for explicating such knowledge (Collins 2010, 1). An element of tacit knowledge can be explicated by elaboration or transformation, by creating a mechanism that imitates a tacit skill or process, or by providing a scientific explanation for it (Collins 2010, 81). In case of weak (relational) and medium (somatic) tacit knowledge explication of at least some elements of knowledge is possible in one or several senses of "explication". At least in principle, one can explicate elements of relational tacit knowledge (explicable knowledge that remains tacit for contingent reasons) one possesses. For instance, one can explain step by step how one handles a piece of laboratory equipment in a particular way (see Collins 2010, 91-98 for the discussion of relational tacit knowledge). At least in principle, one can explicate elements of somatic tacit knowledge. For instance, one can provide a scientific explanation of the process

${ }^{2}$ In case of Longino's account, knowing a rule can be explained as knowing the difference between an idiosyncratic interpretation of a rule and an interpretation that can be intersubjectively recognised as proper.

3 Polanyi's famous example (Polanyi 1958/2002, 101) is that of a student, observing chest X-rays and listening to experts' discussions, and gradually acquiring the ability to see in X-rays what competent radiologists say they see in them. 
of maintaining one's balance on a bicycle or create a mechanism that imitates this process (see Collins 2010, 99-117 for the discussion of somatic tacit knowledge).

Collins argues that in case of strong (collective) tacit knowledge no explication is possible (see Collins 2010, 119-38 for the discussion of collective tacit knowledge). This kind of tacit knowledge characterises human actions in social context. For instance, riding a bicycle in a street, in addition to maintaining balance, requires knowledge of relevant social rules, ability to interpret them according to the situation, to interact with others and respond adequately to their actions. Acquisition and use of collective tacit knowledge requires the ability to develop fluency in the language and culture of community, to understand and apply rules in a way that is context-sensitive and responsive to changes. According to Collins, such fluency can only be developed in the process of socialisation and subsequent participation in the social life of community. Collective knowledge cannot be acquired once and for all-with developments in life of community, it changes constantly and unpredictably and accordingly keeping this knowledge up to date requires constant contact with community (Collins 2010, 30-31).

Collins's classification suggests that tacit knowledge involved in learning norms, standards and rules of practice may contain different elements. Some of its parts may be relational-they are explicable verbally and only remain tacit because no one has the need, or the willingness, to explicate them. Some of its parts may involve skilful bodily action-somatic tacit knowledge. ${ }^{4}$ In addition to those potentially explicable elements, I suggest that it is what Collins calls collective tacit knowledge that forms the necessary basis for the ability to learn norms.

Collins's account attracts attention to two crucial aspects of this learning. First, rules may be interpreted and applied appropriately or inappropriately, and this appropriateness depends on the context of application. Rules in abstraction can be interpreted in many possible ways; in order for them to play their part in critical practices for blocking subjective biases, a (somewhat) stable intersubjective understanding of the appropriate interpretation is required. Accordingly, in order to be able to use rules one has to acquire with them the knowledge what counts as appropriate performance, and this knowledge has to be acquired by being immersed in community of those who already posses these norms and can make judgements about the appropriateness of their use. Without familiarity with the social context where the norms are applied and the correctness of the application judged, there is no possibility to learn what the correct (and intersubjectively recognisable as such) application of rules means. Thus, a necessary precondition for one's learning to apply norms in order to evaluate one's own, and other', claims is learning them in the context of their application by being socialised in the respective community.

One could concede as much and yet defend Biddle's conclusion by arguing that this learning process has an end-the agent who has once learnt community's norms will have no further need in community. One would thus argue that once the "unencumbered self" has completed scientific education, the self can be said to know the norms and be able to

\footnotetext{
${ }^{4}$ Longino discusses tacit knowledge only once, and it seems that she thinks of it as either relational or somatic-discussing whether it is possible to criticise tacit knowledge-for example, that one should pour liquid in a particular way-she writes that some of this knowledge can be made explicit and the rest can be demonstrated (Longino 2002, 104, fn).
} 
apply them for maintaining one's objectivity by self-criticism. However, I suggest that by taking into account the second aspect of collective tacit knowledge that Collins stressesits changeability - one can argue against this possibility. Norms and accepted ways of their interpetation-what counts as the appropriate or correct application-may change, as community changes. Any attempt to lay down community's norms permanently for future independent use is bound to fail, as these fixed rules will become outdated. As Collins (2010, 132-33) writes, " $[\mathrm{t}]$ he competence shown by the isolated speaker will not last indefinitely; the individual is a temporary and leaky repository of collective knowledge. Kept apart from society for any length of time and the context sensitivity and currency of the individual's abilities will fade". ${ }^{5}$

The standards of scientific practice and critical discussion are not different in this respect: in order for the individual's knowledge to reflect changes in these standards, the individual requires continuous contact with community. Without such contact, knowledge claims that the individual considers objective in light of (once learnt) norms may no longer be acceptable as objective for others, if community's norms or accepted ways of their interpretation have meanwhile changed (recall the example of medical community before and after randomised trials became the standard). The relation between objectivity and potential intersubjective acceptability is crucial here. As noted before, community's norms at any given moment may be effective for blocking individual biases, but if some biases are shared by entire community, they may remain hidden - they will not be exposed in critical dialogue and may remain embodied in community's claims, practices and norms. Discovering such biases and modifying norms accordingly constitutes an improvement in community's objectivity and raises the bar for claims that can be accepted by community as objective. Proposals for such modifications and acceptance of such proposals by community, however, are not something that can be predicted in advance. Thus, in order to keep one's knowledge of norms up to community's standard one has to maintain contact with community.

One may still suggest that an individual could apply once learnt rules in isolation indefinitely so that the resulting claims would satisfy community's standards at the moment one's knowledge of rules was up to date. If some of the rules and the ways to interpret them have not meanwhile changed, one's claims can be potentially recognised as up to the current standard; even if the norms have changed, one can still be recognised as following objectively an outdated standard. In order to exclude this possibility, I turn to Kusch's (2002) argument on rule-following.

The starting point for Kusch's argument is the insight (that Kusch 2002, 97 traces back to Wittgenstein) that it is impossible to talk about rightness (e.g., following a rule in the right way) unless one can distinguish being right and seeming to be right. Developing this Wittgensteinian argument, Kusch argues that sociality is the only resource for sustaining this distinction. In other words, what Kusch calls "private rule-following" (Kusch $2002,176)$ is not possible. In order to demonstrate that I am right as opposed to the situation where it seems to me that I am right, I have to appeal to a standard that is independent

5 In their account of expertise that they approach as resting on the basis of tacit knowledge, Collins and Evans (2007, 3, italics mine) make a similar point: "Acquiring expertise is, therefore, a social processa matter of socialisation into the practices of an expert group-and expertise can be lost if time is spent away from the group." 
from me. Kusch suggests that only continuing participation in community provides such a standard: if it seems to me that I am right but in I am not, others can correct and criticise me; others' agreement that I am right supports the conclusion that I am indeed right and it is not the case that it only seems to me. Self-criticism, for example, relying on the memory about one's past self (or imagining the self as a community of self s "slices") cannot provide a basis comparable to that provided by criticism from community. As Kusch $(2002,190$ 91) points out, in interactions with others one can be surprised by their criticisms and encounter resistance in a way that one's yesterday's self cannot surprise or resist today's.

Being able to use even already learnt rules correctly is thus impossible without participating in community, because community's reaction to one's performance is the only basis for judging whether rule-following is being done correctly. Without community, it is impossible to control whether one's performance in applying the rule is not slipping. It may seem to the individual that one continues to do what one did when following the rule correctly but in isolation there is no way to establish that one is right about it. Accordingly, an individual in isolation would not be able to follow once acquired standards the same way members of community can thanks to checks on correctness of performance they receive in community.

A similar argument-the need for continuing participation in community in order to learn about various perspectives and to be able to check whether one applies them correctly-can be made in case of evaluation in light of different perspectives as a precondition of objectivity. Longino's argument for the necessity of social inclusiveness makes it easy to see this precondition in terms of tacit knowledge, although she does not use the term herself. Discussing the damage to objectivity caused by exclusion of certain social groups from scientific community, she focuses on a particular perspective that is based on belonging to a particular group rather than on any explicitly formulated and adopted body of knowledge. The requirement of inclusiveness means that the kind of knowledge in question cannot be separated from its bearer and fully presented in explicated form, or it would not be necessary to demand actual presence of bearers of different perspectives in scientific community. Thus, according to my interpretation of this requirement of Longino's, inclusion of various social groups benefits scientific community, as it gives each member the possibility to learn about perspectives based (among other factors) on different tacit knowledge.

The knowledge involved may be in turn analysed in Collins's terms as containing different types of tacit knowledge. Bringing a particular perspective into discussion may include different elements, including what is, or can be, explicitly stated. However, such a perspective is ultimately grounded in the social experience its bearer has and thus can only be fully acquired by having this kind of social experience, by being socialised in the respective community. This means that to the degree that a perspective depends on particular social experience one cannot imitate it if one does not possess this experience. Accordingly, individuals in isolation from communal dialogue may not be able to generate some of relevant perspectives on their own. One may still be able to think of some alternatives; the point is, their variety will be limited compared to that potentially available in an inclusive community. The difference between the self-generated challenge and the challenge that comes from others that Kusch mentions is also relevant here-it seems plausible that one can be genuinely surprised by criticism originating from someone else's perspective in a way one cannot surprise oneself. Thus, the only way to benefit fully from a variety of perspectives is to take part in communal dialogue where persons with different social experience and collective knowledge participate. An attempt to lay down perspectives for future individual reference-for instance, by laying 
down all points of view that are currently recognised in communal discussion as relevantwould encounter the already mentioned problem of becoming obsolete. Collective knowledge that members of different social groups possess evolves constantly and the perspectives they bring to communal dialogue evolve with it.

Learning about the necessary variety of perspectives thus requires continuing contact with community just like in case of norms. Similarly, applying a perspective correctly requires continuing participation in community so that one's performance can be checked and corrected. Without this kind of community's control the isolated individual runs into the familiar impossibility of distinguishing being right (I use this perspective as the basis of evaluation and generate criticisms on its basis correctly) and seeming right (it seems to me that I use this perspective for criticising my claims correctly). Again, I conclude that the individual in isolation would not be able to do what an inclusive community can - to evaluate claims in light of as large a variety of alternative perspectives and to have means for distinguishing correct and seemingly correct use of these perspectives.

To sum up, I have discussed certain preconditions of criticism for maintaining objectivity, using Collins's and Kusch's arguments, and concluded that objectivity cannot be fully realised by individuals in isolation from community even if they are completely impartial and open-minded. Thus, I reject Biddle's claim that "unencumbered selves" would not need community for achieving objectivity.

It is important to discuss how this conclusion should be understood in the context of my response to Biddle. I have argued that the work on tacit knowledge and rule-following supports the conclusion that objectivity, to the degree it involves evaluation of one's position in light of some norms and some alternative perspectives, is impossible without community even for "unencumbered selves". Accordingly, I reject Biddle's claim that Longino's account is not necessarily social if it presupposes "unencumbered selves"-according to my argument, such an account would still be fundamentally social.

At the same time, it is important to keep in mind that I argue for the social nature of such an account on a basis that Longino might not herself accept and that is not a part of her actual argument. The aim of the discussion of the current section is to resist the conclusion of Biddle's argument: I argue that even if his reading of Longino is correct, there are independent grounds to argue that "unencumbered selves" are not able to achieve objectivity, as Longino describes it, in isolation. However, it does not touch Biddle's claim that Longino's account as it is presupposes the problematic notion of the "unencumbered self". The aim of the second line of my argumentation is to address this issue directly. I attempt to show that in Longino's text there is evidence for a different conception of the knowing subject and that the "unencumbered self" is neither strictly necessary nor desirable for the realisation of Longino's idea of objectivity. ${ }^{6}$

\section{Objectivity for "encumbered selves"}

Biddle's argument about the conception of the individual in Longino's account is based first on the interpretation of Longino's own text and second on seeing her account as

${ }^{6}$ Previously, I briefly addressed this issue in Eigi 2012, 59-61. 
closely related to Mill's and sharing Mill's conception of the individual. My argument is similarly based on reading Longino's text and looking at her account through the lens of Mill's argument.

In order to question Biddle's interpretation of Longino's conception of the individual in the most straightforward way, I turn to Longino's own discussion of the conception of the individual in her epistemology. Describing her account, Longino $(2002,9)$ claims that her ambition is to develop an epistemology for non-idealised subjects- "epistemology for living science, produced by real, empirical subjects". These empirical subjects, in turn, are understood as limited in their ability to be open and impartial-Longino $(2002,107)$ remarks that the important lesson of sociological studies of science is the realisation that epistemic subjects are historically, geographically and socially located, and their locatedness matters for knowledge they produce. Thus, the acknowledgement that individuals are influenced by a particular historical, social and cultural context and their openness is therefore inevitably limited is an integral part of her account. Elsewhere, discussing various conceptions of the individual in social epistemology, Longino $(2002,147)$ mentions Michel Foucault's idea of "the death of the subject". She interprets it as applicable to the idealised subject of the traditional epistemology - the subject that is "capable of the view from nowhere", the "unconditioned (or universally conditioned) Subject". Longino does not defend this conception. Instead, she argues that giving it up leaves open the question about the non-idealised subject-the "embodied, socially located, and culturally conditioned" (Longino 2002, 147) individual. This is the individual that epistemology has to be developed for. Thus, for Longino the absolutely open self is neither an adequate description of real subjects nor the model object for epistemology.

Another confirmation of the limited openness of individuals can be seen in Longino's justification for the need to include various social groups in scientific community. Longino stresses that it is not that marginalisation creates an objective perspective; it is representation of different perspectives that is crucial for objectivity (Longino 1990, 82, fn) - as there are no fully impartial knowers, objectivity has to be achieved on the basis of a variety of partialities.

In this idea of "situated" selves there can be seen important similarities with the conception of the individual Biddle himself defends. Biddle contrasts the conception of the "unencumbered self" that is open to any criticism and does not have deep connections with any communities, ideas or ways of life, with the notion of the "advocate" (Biddle 2009, 620-22). Due to socialisation in a particular scientific community and deep connections with a particular research programme, scientists as advocates have less openness to criticism and more persistence in pursuing the line of research they are committed to. Biddle argues that this kind of "advocacy" is ultimately beneficial for the advancement of science. I suggest that in discussing the inevitable social and cultural locatedness of the knowing subject Longino's account similarly acknowledges this inescapable "advocacy" aspect of the individual.

Thus, in Longino's text there is evidence that she explicitly rejects the conception of the "unencumbered self", which Longino calls the "unconditioned self", for a conception of the individual whose openness to criticism is inevitably limited. Despite that, one may suggest that this ideal of the individual is implicit in her account because it is what the full realisation of the criterion of uptake presupposes. If Longino's criterion of uptake is to be understood individualistically, as Biddle argues, the ideal subject to realise this criterion is the 
one who is capable to heed to all possible criticism, "unencumbered" by any commitments. The following part of my argument aims to challenge this individualistic interpretation of uptake drawing on certain statements Longino makes about the functioning of the ideal of objectivity.

Crucial for my argument is Longino's explanation that in her account objectivity does not presuppose a particular "objective" attitude on part of each individual but instead relies on the operation of community practices: "The objectivity of individuals in this scheme consists in their participation in the collective give-and-take of critical discussion and not in some special relation (of detachment, hardheadedness) they may bear to their observations" (Longino 1990, 79). The ability for full detachment from one's beliefs that Biddle describes as the crucial attribute of the "unencumbered self" thus is not a necessary condition for taking part in community dialogue and by doing so helping to sustain objectivity of community. However, if each individual is not required to be responsive in this way, it is the community level where responsiveness should be ensured. Elsewhere Longino confirms that her account focuses on the social rather than the individual level: her norms are directed at community structures and processes rather than individuals (Longino 2002, 145). This statement similarly supports the social interpretation of uptake, rather than the individualistic sense Biddle suggests. In light of Longino's insistence about the primacy of the communal level, Longino's requirement that "community members pay attention to the critical discussion" that Biddle $(2009,617)$ quotes in support of his interpretation, can also be read as requiring responsiveness on the community level while allowing some variation in responsiveness on part of each individual.

A community may remain objective, block individuals' claims that fail to satisfy its standards from acquiring the status of public knowledge and be responsive to alternative perspectives represented in community, even if the individual behind a particular claim does not acknowledge relevant criticism and continues to uphold the claim. Longino describes the production of scientific knowledge as the result of collective practices. Modification of the initial claim does not have to be made by its author-as Longino writes, "[i]f the original proponent does not [modify claims and assumptions in response to criticism], someone else may do so as a way of entering into the discourse" (Longino 1990,73). Whether a particular claim becomes a part of accepted public knowledge is not determined solely by its author but depends on collective activities in community.

Longino mentions peer-review as an evident example of such critical activity and points out that criticism does not end with publication (Longino 1990, 68-69). Extending her example, I suggest seeing members of scientific community as continuously taking part in acts of criticism and response: by subjecting claims to peer-review and responding to criticism received, by providing criticism as peer-reviewers and subsequently judging the adequacy of the author's responses, by choosing to cite or not to cite a particular claim, to use or not to use particular data, to attempt to replicate someone's experiment or to take part in discussion over a published paper they all contribute to the collective practice as the result of which individuals' claims are integrated into collective knowledge.

Given this ongoing process of criticism, some responsiveness to criticism on part of each member is necessary (one cannot be a member of contemporary scientific community without being ready to subject one's work to peer-review). At the same time, each particular critical challenge may allow a variety of responses (to retract one's claim or to change it as requested by the reviewer; to provide additional arguments to support the 
initial claim; to take the paper elsewhere where it would not raise similar criticism; to incorporate response to previous criticisms into the next paper etc). In doing so, each individual may demonstrate both openness to criticism in some respects and unwillingness or inability to change in response to criticism in others. However, as individuals' claims do not become a part of community's knowledge automatically, this inability needs not threaten community's ability to be objective. The ability of the individual for the detachment and control over one's subjective biases is less important than the organisation of communal practices, and the limitations of this individual ability are not fatal for community's objectivity. Therefore, as complete openness of individuals is not necessary for successful critical dialogue in Longino's account, there is no need to suggest that an "implicit" conception of the individual capable of such openness is necessary in order to make her account work.

I develop this argument further suggesting that limited openness to criticism is not only non-threatening but can also be to some degree desirable for maintaining objectivity in Longino's account. In order to do so, I turn to discussing some aspects of Mill's argument that Biddle overlooks.

As Biddle justly stresses, Mill's ideal individual — the “wise man” $(1859 / 1978,19)$ —is someone capable of listening to all possible objections and potentially ready to change any of beliefs in response to them. This, as Biddle argues, presupposes the ability to distance oneself from one's most central beliefs in the way that is associated with "unencumbered selves". Acknowledging that, I nevertheless suggest that there are other strands in Mill's writings. I interpret them as supporting the view that not everyone is required to show this degree of detachment and community can live with, and benefit from, having less responsive members. In other words, I argue that some aspects of Mill's argument can be interpreted as supporting the social interpretation of responsiveness.

The aim of Mill's defence of freedom of discussion is to show that it is community that benefits from toleration of dissenting opinions-silencing an opinion is not "simply a private injury", but an act of "robbing the human race" (Mill 1859/1978, 16). It is above all the majority, those holding the currently domineering opinions that enjoys the benefits that Mill associates with free discussion-the replacement of false opinions with true ones, the completion of incomplete true opinions and the better appreciation of the meaning and justification of complete truths.

This benefit, in turn, is the greater the stronger are the dissenter's opinions and the more vigorous their defence: "He [the one holding the dominant opinion] must be able to hear them, dissenting opinions, from persons who actually believe them, who defend them in earnest and do their very utmost for them" (Mill 1859/1978, 35). While Mill welcomes the ultimate convergence of opinions on the true one, he also stresses that losing the benefit of having persistent and eager opponents is "no trifling drawback" (Mill 1859/1978, 42) of this process. As long as it is not completed, community should welcome those defending deeply held alternative views and see them as a fortunate "spontaneous" opportunity to test the domineering views against the most serious objections, and "rejoice that there is someone to do for us what we otherwise ought ... to do with much greater labour for ourselves" (Mill 1859/1978, 43). Neither are limitations of openness on part of those defending alternative opinions necessarily problematic, particularly given the imperfect state of community: "so long as popular truth is one-sided, it is more desirable than otherwise that unpopular truth should have one-sided assertors, too” (Mill 1859/1978, 44). 
Thus, the presence of those unwilling or unable to question certain of their opinions"advocates", "conditioned selves"- does not necessarily threaten community's pursuit of truth. Instead, it benefits community as long as there is enough of those who are capable of questioning and improving their opinions in light of opposing views-enough of those whom Mill characterises as "the calmer and more disinterested bystander" on whom "this collision of opinions works its salutary effect" (Mill 1859/1978, 49). While such disinterestedness remains the ideal for the individual, the community as a whole may operate successfully as a "free marketplace of ideas" even if not every of its members realises this idealin other words, there are reasons to talk about the collective, rather than the individualistic interpretation of the requirements posed by the ideal. Looking at Longino's account as embedded in Mill's thus may be compatible with interpreting the criterion of uptake socially.

Again, it is important to pause and discuss the impact of my conclusions on Biddle's argument. Biddle argues that both Longino's and Mill's texts point in the direction of the individualistic interpretation of uptake. In this section, I attempted to show that this interpretation fails to take into account other important claims made by Longino and Mill. Longino's repeated denial of the possibility of the "unconditioned self" and her insistence that the discussion of objectivity is to focus on the community-level processes contradict the reading Biddle proposes. Even Mill, who sees openness to criticism as the only possible basis for "wisdom", may be read as supporting the social interpretation of this openness, as he describes how community as a whole can benefit from passionate and persistent proponents of alternative views. I conclude that the reading Biddle proposes is ultimately inadequate, missing important strands of Mill's and Longino's thought.

At the same time, Biddle's argument attracts attention to an important tension in Longino's account. I suggest that some of this tension may be attributed to the relation between the individual and the social-level kinds of uptake that I mentioned previously. For a community to be responsive, at least some of its members must be; accordingly, even for a proponent of the social interpretation of uptake, improvement of the responsiveness will require the growth of the number of responsive individuals and the degree of their responsiveness - and the openness of the "unencumbered self" may be seen as the ultimate stage of this development. I have attempted to show that Longino approaches knowing subjects as situated and thus incapable of complete openness as a matter of fact and that Mill describes the way community could benefit from such an inability, but this tendency remains an important source of ambiguity. What I have attempted to show is that this ambiguity does not undermine the social character of Longino's account in the way that Biddle argues it does.

\section{Conclusion}

In the paper, I challenge Biddle's denial of the social nature of Longino's account in two different ways. First, going beyond Longino's account, I reject the general idea at the centre of Biddle's argument-the idea that the "unencumbered self" that Biddle sees as the conception of the individual underlying Longino's account would alone be able to be objective in the same way as community is. Drawing on Collins's and Kusch's ideas I argue that a crucial element of objectivity - being able to evaluate one's and others' claims in light of non-subjective norms and alternative perspectives-can be acquired, kept up to date and 
applied correctly only through socialisation and continuing participation in community. Second, I argue that Biddle's interpretation of Longino fails to take into account important aspects of her position. In her text, Longino explicitly adopts the conception of the located and conditioned self and stresses the importance of approaching objectivity on the level of community. Moreover, it is possible to make an argument that community as a whole can benefit from "encumbered selves" and thus that requiring the fulfilment of the ideal of openness from everyone is not strictly necessary. I conclude that contrary to Biddle's claim, there are strong reasons to characterise Longino's account of objectivity as social, both in seeing community as necessary for objectivity and in seeing the knowing subject as socially located and conditioned. More generally, the necessity of community for critical evaluation of one's and others' claims means that any account that focuses on criticism has to be social.

\section{REFERENCES}

Biddle, Justin B. 2009. Advocates or Unencumbered Selves? On the Role of Mill's Political Liberalism in Longino's Contextual Empiricism. Philosophy of Science, 76 (5): 612-23.

Collins, Harry. 2010. Tacit and Explicit Knowledge. Chicago; London: The University of Chicago Press.

Collins, Harry and Robert Evans. 2007. Rethinking Expertise. Chicago; London: The University of Chicago Press.

Eigi, Jaana. 2012. Two Millian Arguments: Using Helen Longino’s Approach to Solve the Problems Philip Kitcher Targeted with His Argument on Freedom of Inquiry. Studia Philosophica Estonica, 5 (1), 44-63.

Kusch, Martin. 2002. Knowledge by Agreement: The Programme of Communitarian Epistemology. Oxford: Clarendon Press.

Longino, Helen E. 1990. Science as Social Knowledge: Values and Objectivity in Scientific Inquiry. Princeton: Princeton University Press.

Longino, Helen E. 2002. The Fate of Knowledge. Princeton; Oxford: Princeton University Press.

Mill, John Stuart. 1859/1978. On Liberty. Indianapolis: Hacket Publishing Company Inc.

Polanyi, Michael. 1958/2002. Personal Knowledge: Towards a Post-Critical Philosophy. London; New York: Routledge.

JAANA EIGI received her MA in philosophy from the University of Tartu in 2009. Currently she is writing her PhD thesis on the social organisation of science and working as a research assistant at the chair of philosophy of science of the University of Tartu. Her primary research interests are social aspects of science, the social organisation of science and the relations between science and society.

Address: Department of Philosophy, University of Tartu. Ülikooli 18, 50090 Tartu, Estonia. jaana.eigi@ut.ee 